\title{
Research on aerodynamic characteristics through airflow clearances in compressor blades of gas turbine engine
}

\author{
Quoc Toan Tran ${ }^{*}$, Ngoc Thanh Huynh, Thanh Quyet Pham
}

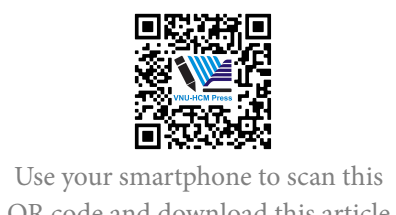

QR code and download this article

Faculty of Electro-mechanics, Vietnam Naval Academy, Vietnam

Correspondence

Quoc Toan Tran, Faculty of Electro-mechanics, Vietnam Naval Academy, Vietnam

Email: quoctoannhatrang@gmail.com

History

- Received: 9-12-2020

- Accepted: 18-12-2020

- Published: 31-12-2020

DOI : 10.32508/stdjet.v3iSI3.640

\section{Check for updates}

\section{Copyright}

(c) VNU-HCM Press. This is an openaccess article distributed under the terms of the Creative Commons Attribution 4.0 International license.

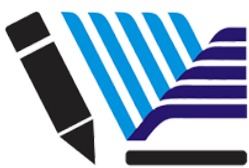

VNU-HCM Press

\begin{abstract}
Abstract: Reducing the loss in the airflow clearance among the compressor blades of the rotor disk and stationary blades (guide vanes) is an urgent issue. Furthermore, additional losses of airflow through the clearances among the blades and airfoil losses are the main cause of reducing the efficiency of an axial flow compressor, especially the blade height is small. With a view towards the efficiency improvement of a multistage axial compressor with a high-pressure ratio, it is necessary to manufacture a highly economical compressor with a variety of compression stages. Airflow in the circulation clearances alternating among compressor blades has viscosity, unstable compression, and quite complex flow structure. This needs to be researched into the design with the assistance of modern software (ANSYS CFX, FlowER, etc.). Although this is an important step in the current design orientation, it requires additional practical elements to perform, especially the problem of optimizing the outer rim, the level, and the number of compression stages in the whole compressor. In this paper, authors have used the method of creating three-dimensional (3D) models for blade profiles in a compressor based on analyzing the flow in three-dimensional form and studying their parameters. This paper deals with the geometry problems of the row of rotating blades (cascade) by proposing the structural arrangement of stacking blades in the circular direction and the blade profile formed the S-shape. Investigating and calculating the aerodynamic properties of the airflow through clearances of compressor blades by using ANSYS is one of the new methods. The researched result showed the dependence between the camber angle as the rotating blade formed an S-shape profile rotates regarding the stagger angle of the airfoil and the incident angle of airflow. Some characteristics of aerodynamic properties are distributed according to the blade height in conducting with different curved profiles of the rotating blades on the rotor disk and stationary blades.
\end{abstract}

Key words: compressor blades, blade profile, camber angle, rotating blade, annular cascade, loss coefficient in airflow clearances

\section{INTRODUCTION}

With a view towards the efficiency improvement of a multistage axial compressor with a high pressure ratio, it is necessary to manufacture a highly economical compressor with variety of compression stages. Air flow in the circulation clearances alternating among compressor blades has viscosity, unstable compression and quite complex flow structure. This needs to be researched into design with the assistance of modern software (ANSYS CFX, FlowER, etc.) ${ }^{1}$. Although this is an important step in the current design orientation, it requires additional practical elements to perform, especially the problem of optimizing the outer rim, the level and number of compression stages in the whole compressor. In this paper, authors have used the method of creating three-dimensional (3D) models for blade profiles in a compressor based on analyzing the flow in three-dimensional form and studying their parameters.

\section{MATHEMATICAL MODEL AND METHODS}

As well known, reducing the loss in the airflow clearance among the compressor blades of the rotor disk and stationary blades (guide vanes) is an urgent issue. Furthermore, additional losses of air flow through the clearances among the blades and airfoil losses are the main cause of reducing efficiency of an axial flow compressor, especially the blade height is small. One of the methods to improve the structure of the flow in the area of the tip and hub of blade is to use the blades in a annular form (the slope of the blade profile in the circular direction). The use of a row of annular (annular cascade) blade results in a redistribution of the load along the section of the compressor blade profile ${ }^{2}$ and structural changes in the unstable influence of the rotating blades and stationary blades. The change in pressure and efficiency regarding the blade height depends on the entire load of the compression 
stages. However, the information on the different effect of the annular form to the parameters of compressor stages is contradictory. Analyzing the impact of radial clearance, it is reasonable to use blades with blade cross-section in S-shaped boundary areas to reduce the intensity of turbulance through the clearance. A similar blade profile (according to the entire blade height) was created according to the ultrasonic arrays, when controlling the diffusion of airflow clearances alternating among the blades, so that the airflow resistance on the blade trailing edge is suitable. The use of the special profile of the compressor blade in the compressor stages of multistage compressor of gas turbine engine increases their efficiency.

The use of a annular cascade with an S-shaped profile can provide significant efficiencies in both the first and last compression stage. However, the information available in the document is not codified and is not suitable for actual use. Specifically, the effect of the annular cascade on the characteristics of the compression stage in the wide flow range and the outlet blade angle at the outlet of the compression channels is unclear. There is not enough information about the distribution of the loss coefficient along the blade section in introducing a annular cascade and S-shaped blades. Therefore, to implement these methods is to require initial detailed analysis, especially by Computational Fluid Dynamics (CFD) method.

\subsection{Geometry model}

The issue is to create a geometric model of the row of rotating blades and stationary blades of the compressor stages, when applying the structure of the blades is annular in the circular direction and S-shaped profiles have been solved by automated design systems and ANSYS simulation software.

We consider that the aerodynamic profile of airflow clearance among the compressor blades are formed due to the symmetric deformation of the initial blade profile. The center line of the original profile is curved according to a certain rule so that the angles are at its intersection points with the horizontal axis at coordinates $(0 ; 0),(\mathrm{Bi} ; 0)$ in the original coordinate system respectively $\gamma_{1 i}$ and $\gamma_{2 i}$ (the horizontal axis represents the arc of the blade profile, the vertical axis perpendicular to the horizontal axis) (Figure 1). The positive direction of the horizontal axis is taken from the tip to the hub of the blade. The camber line in a curved airfoil of the blade may be represented by an arc, a hyperbolic arc, or as a representation of polynomials ${ }^{3}$ :

$$
Y_{i}=a+b \cdot X_{i}+c . X_{i}^{2}+d . X_{i}^{3}+f . X_{i}^{4}+e X_{i}^{5}
$$

To find the coefficients (a, b, c, d, f, e), as well as the quantities, we solve the system of equations (2) with some radius value $R_{i}$. The first five equations represent the initial geometry of the camber line in the coordinate system (Figure 1), the sixth and seventh equations assume the shape of the camber line as an arc at leading edge of the blade profile (in the distance $\frac{B_{i}}{25}$ and $\frac{B_{i}}{30}$ in the arc). The eighth equation describes the S-shaped profile at the trailing edge of the blade (Figure 2).

where: $\mathrm{i}$ - the number of cross-sectional areas according to blade height; ( $a, b, c, d, f, e)$ : coefficient of the polynomial; $B_{i}$ - length of chord at the radius $R_{i}$ of the blade profile; $\left(\bar{X}_{f i}\right)$ : coordinate of the maximum deflection of the contour average at the radius position $R_{i} ; \gamma_{1 i}$ and $\gamma_{2 i}$ - the camber angle of the camber line at the point of intersection with the horizontal axis at the radius position $R_{i} ; \theta_{i}$ - the stagger angle of the blade profile at a radius position $R_{i} ; P_{S i}$ - the $S$-shaped parameter of the camber line of the blade profile; $\left(\beta_{y c t i}\right)_{g n}$ - the initial air inlet angle of airflow clearance at the radius position $R_{i}$ (when $P_{S i}=0$, $\left(\beta_{1 r i}\right)_{g n}$ - the initial blade inlet angle at position $\left.R_{i}\right)$; The parameter $P_{S i}$ change can be made according to a defined rule along the blade height within the range $P_{S i}=\left(0 \div\left(P_{S i}\right)_{\max }\right)$, where $\left(P_{S i}\right)_{\max }$ - the maximum value of the parameter when $\gamma_{2 i} \approx 0$.

When increasing the parameter $P_{S i}$ corresponds to the larger S-shaped profile at the air oulet angle. Recalculating the coordinates of the blade profile from the coordinate system (Figure 1) to the basic coordinate system, taking into setting of air inlet angle is determined by:

$$
\beta_{y c t i}=\beta_{1 r i}+\gamma_{1 i}
$$

$$
\begin{aligned}
& X_{c b i}\left(X_{i}\right)=X_{i} \cdot \cos \left(\beta_{y c t i}\right)-Y_{i}\left(X_{i}\right) \sin \left(\beta_{y c t i}\right) \\
& Y_{c b i}\left(X_{i}\right)=X_{i} \cdot \sin \left(\beta_{y c t i}\right)+Y_{i}\left(X_{i}\right) \cos \left(\beta_{y c t i}\right)
\end{aligned}
$$

where: $\beta_{y c t i}$ - air inlet angle; $X_{c b i}\left(X_{i}\right), Y_{c b i}\left(X_{i}\right)$ - coordinates of the contour average line at the basic coordinate system.

Here we consider that the contour of the annular blades in the circular direction, by making the axis of the center of the blade form a curve, when the axial position of the center of mass at a radius $R_{i}$ is determined by the angle $\theta_{2 i}$ (the angle of rotation of the Zaxis around the $\mathrm{X}$-axis, the direction from the $\mathrm{Z}$-axis to the Y-axis).

The mean camber of profile of each cross-section according to the blade, height of the symmetrical coordinates of the profile, the radius value of the leading 


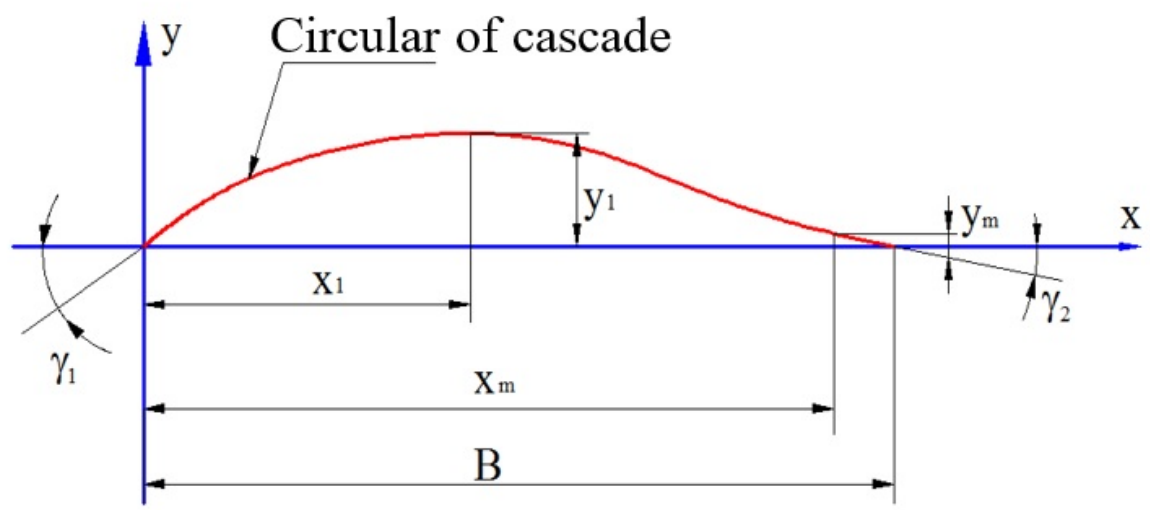

Figure 1: Diagram of the average of the original profile in the original coordinate system

$$
\begin{aligned}
& (a=0 \\
& \operatorname{tg}\left(\gamma_{1 i}\right)=b_{i} \\
& \operatorname{tg}\left(\gamma_{1 i}+\theta_{i}\right)=b_{i}+2 \cdot c_{i} \cdot B_{i}^{2}+4 \cdot f_{i} \cdot B_{i}^{3}+5 \cdot e_{i} \cdot B_{i}^{4} ; \gamma_{2}>0 \\
& 0=b_{i}+2 \cdot c_{i} \cdot\left(\overline{X_{f i}}\right)+3 \cdot d_{i} \cdot\left(\overline{X_{f i}}\right)^{2}+4 \cdot f_{i} \cdot\left(\overline{X_{f i}}\right)^{3}+5 \cdot e_{i} \cdot\left(\overline{X_{f i}}\right)^{4} \\
& 0=a_{i}+b_{i} \cdot B_{i}+c_{i} \cdot B_{i}^{2}+d_{i} \cdot B_{i}^{3}+f_{i} \cdot B_{i}^{4}+e_{i} \cdot B_{i}^{5} \\
& \left\{a_{i}+b_{i} \cdot\left(\frac{B_{i}}{25}\right)+c \cdot\left(\frac{B_{i}}{25}\right)^{2}+d \cdot\left(\frac{B_{i}}{25}\right)^{3}+f \cdot\left(\frac{B_{i}}{25}\right)^{4}+e \cdot\left(\frac{B_{i}}{25}\right)^{5}=\left[\sqrt{\left(\frac{B_{i}}{2 \cdot \sin \left(\gamma_{1}\right)}\right)^{2}-\left(\frac{B_{i}}{25}-\frac{B_{i}}{2}\right)^{2}}\right]-\frac{B_{i}}{2 \cdot \tan \left(\gamma_{1 i}\right)}\right. \\
& a_{i}+b_{i} \cdot\left(\frac{B_{i}}{30}\right)+c \cdot\left(\frac{B_{i}}{30}\right)^{2}+d \cdot\left(\frac{B_{i}}{30}\right)^{3}+f \cdot\left(\frac{B_{i}}{30}\right)^{4}+e \cdot\left(\frac{B_{i}}{30}\right)^{5}=\left[\sqrt{\left(\frac{B_{i}}{2 \cdot \sin \left(\gamma_{1}\right)}\right)^{2}-\left(\frac{B_{i}}{30}-\frac{B_{i}}{2}\right)^{2}}\right]-\frac{B_{i}}{2 \cdot \tan \left(\gamma_{1 i}\right)} \\
& P_{S i} \cdot\left(\theta_{i}-\left(\left(\beta_{y c t i}\right)_{g n}-\beta_{1 r i}\right)\right)+\left(\left(\beta_{y c t i}\right)_{g n}-\beta_{1 r i}\right)=\gamma_{1 i}
\end{aligned}
$$

Figure 2: The eighth equation describes the S-shaped profile at the trailing edge of the blade.
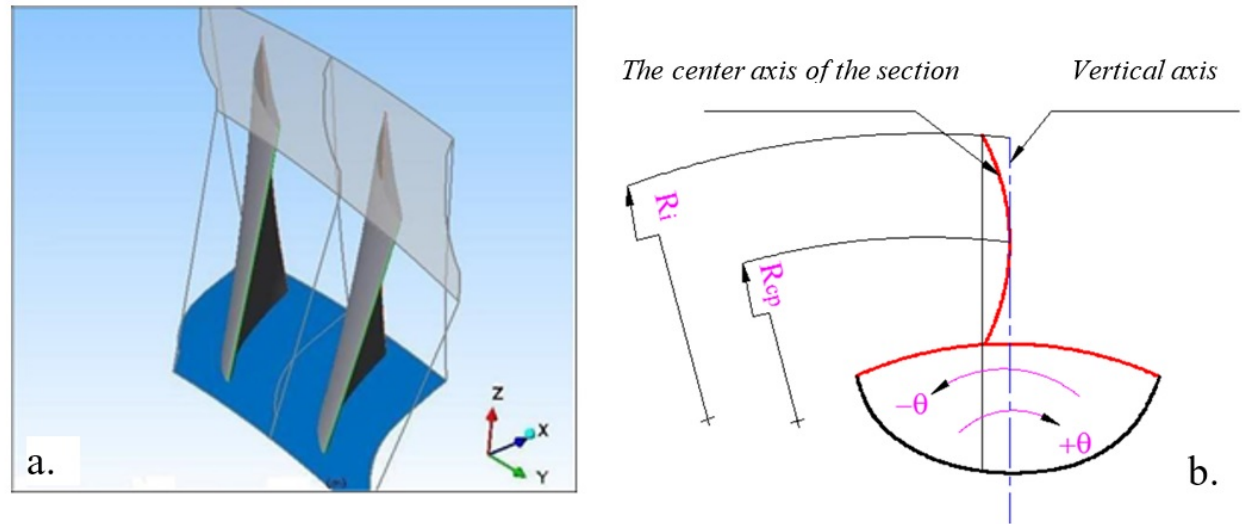

Figure 3: Calculation scheme for stacking structure of blades a. Diagram of a circulation gap between two blades b. Diagram of a annular structure in circular direction 
and trailing edges, the relative maximum thickness of the blade profile $\left(\bar{C}_{\text {maxi }}\right)$; value of $\theta_{2 i}$ is formed by the geometry of the blade profile.

We use ANSYS software to create a solid-state geometry model with the shape of the compressor blade, with additional data such as the shape of the camber line according to the blade height, predetermined dependent coefficients in polynomial (2), taking into inlet blade angle and shape of the camber line (these coefficients and values are calculated and included from the Mathcad program). This method is to create a blade profile to use calculations in the CFD calculation program. The results obtained are the influence of the changes of the blade's geometry parameters such as: the annular in the circular direction (angle $\theta_{2 i}$ ), the degree of S-shaped curvature (parameter $\left.P_{S}\right)$, the flow structure and the aerodynamic characteristic of compression stages.

\section{Research object}

To assess the influence of the S-shaped profile of camber line to its characteristics, we consider that the intermediate levels of the high pressure compressor in gas turbine engine ${ }^{4}$ (Figure 3 ).

The shape of blade is done according to the invariant law of the circulation along the blade height. In order to establish the turbulent flow at the entrance of the compressor during the calculation, it is necessary to assume the geometric change of the inlet guide vanes at the compressor inlet.

\section{Methods}

When constructing the computation range for a cascade $^{5}$, we enter a parameter for meshing (the repetitive part of the wing is considered), with a partition of about $3.5 \times 10^{6}$ nodes in a loop. Parameters $y^{+}$are controlled in the calculation process such that $y^{+}<3$. Method of making interference, with interference level at compressor entrance is $5 \%$. The computational problem is considered when combining the boundary condition of the total pressure at the inlet with the problem of the direction of flow - the static pressure at the outlet. Use the average at the boundary of the computational domain of the neighboring rings. The criterion of the calculation is to establish the basic integral properties of the flow, when the minimum value of the middle square of the flow is reached. In the simulation, maintain the Reynol coefficient $R_{e}>2.10^{5}$ by setting physical conditions (real conditions) at the entrance to the calculation area.

\section{RESULTS AND DISCUSSION}

Analyzing the influence of the S-shaped profile of the camber line along the blade height to the characteristics of the airflow clearances in compressor

In the first stage, determining the effect of the shape change of the camber line profile according to the blade height to the loss coefficient, air outlet angle from airflow clearances, diffusion coefficient $\mathrm{D}$.

The study was carried out in the calculation mode according to the flow mass, rotational frequency of the rotor $\left(\bar{n}_{n p}=1.0 ; \bar{G}_{B n p}=1.0\right)$.

The study follows 12 alternatives for the geometry of the impeller (Table 1, here $\left(P_{S}\right)_{\max }$ - the value of the parameter $P_{S}$ when $\left.\gamma_{2}>0\right)$.

The density of the clearance among the rotating blades is made up at the mean radiusis $\frac{b}{t}=1.16$, the relative bladeheight $\frac{h}{b}=1.37$, the size of chord $b=36.6 \mathrm{~mm}$, the coefficient $\bar{H}=0.263, \bar{C}_{1 a}=0.45$.

According to the CFD results ${ }^{5}$, it is found that, when the camber line of the profile is S-shape, the angle of resistance at the trailing edge will decrease. This change is larger than the effect of the parameter $P_{S}$ on airflow resistance. At the same time, when the concentration $\bar{C}_{1 a}$ increases the diffusion coefficient D increases, leading to a change in the distribution of the loss coefficient in the airflow clearance according to the blade height.

The results obtained according to the distribution of loss coefficients (Figure 5) are unreliable and need further examination by testing. In the second phase, solve the problem of determining the resistance angle of the flow in the trailing edge from the airflow clearances with the shape of the camber line of the Sshaped blade and when the incident angle of the airflow is nearly optimal.

In order to get the dependence of the resistance angle on the geometry of the rotaing blades, use the layout diagram of the orthogonal centers. In this case, the parameter $P_{S}$ changes within $P_{S}=(0.06 \div 0.34)$; average deflection of the cross-sectional profile of the blade $\left(\bar{X}_{f}=0.4: 0.5\right)$, the air inlet angle of the channels $\left(\beta_{1}=33 \div 43^{\circ}\right)$, the parameter of rotation speed $\omega^{2} R=(2.29 \div 3.29) .10^{6}$.

When assessing the camber angle of the air flow, use the formula ${ }^{6}$ :

$$
\delta=\delta_{0}+\frac{m}{\left(\frac{b}{t}\right)^{b}} \cdot \theta
$$

where: $\delta_{0}$ - angle of the corner when there is no deflection of the blade profile; $\theta$ - the angle of the blade 


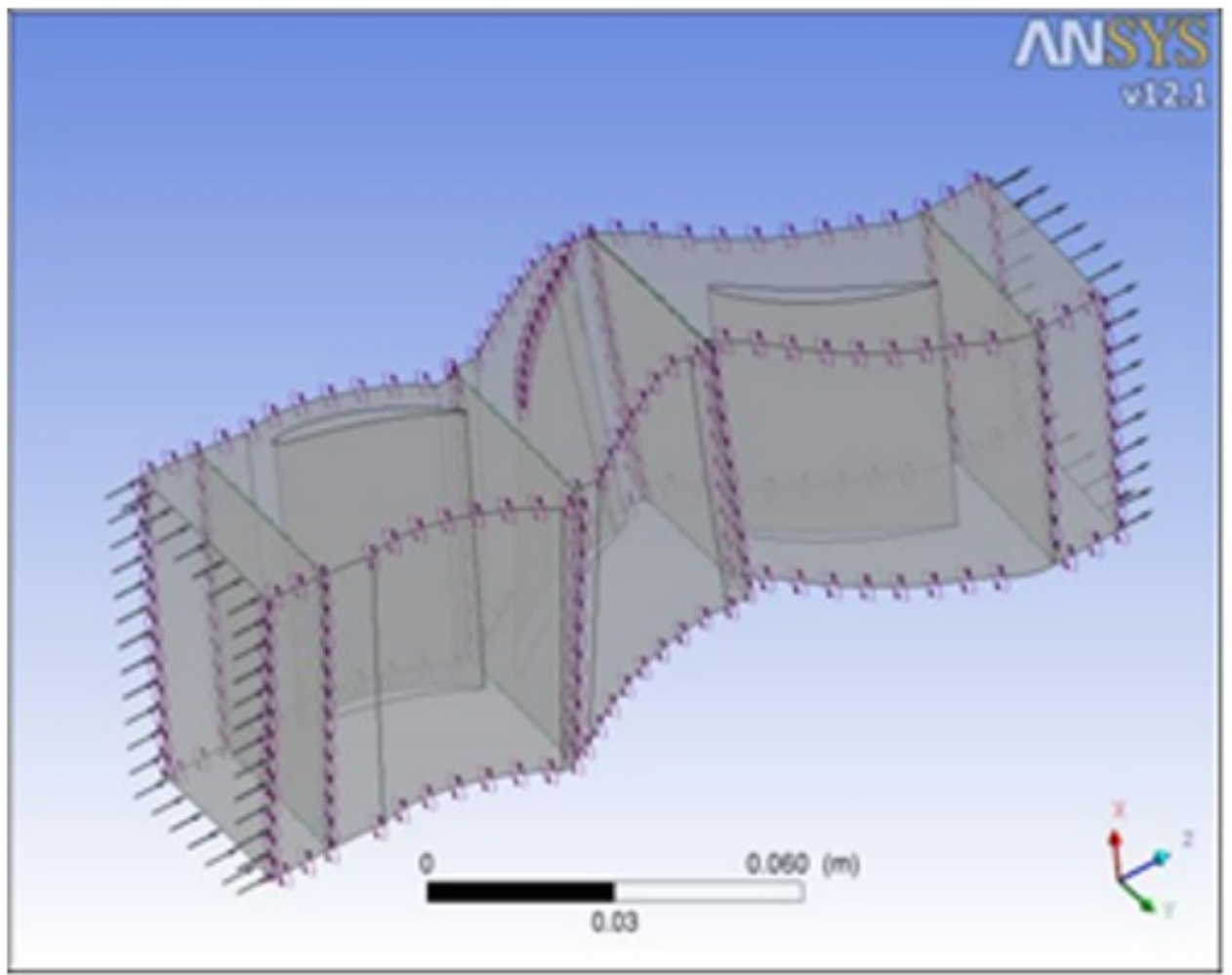

Figure 4: Calculation scheme for investigation in CFD

Table 1: Calculation options on CFD when changing parameters

\begin{tabular}{lll}
\hline Options & Relative blade height & Parameter \\
$1-1$ & 1.0 & $\left(P_{S}\right)_{\max } / 4$ \\
$1-2$ & 1.0 & $\left(P_{S}\right)_{\max } / 2$ \\
$1-3$ & 1.0 & $3\left(P_{S}\right)_{\max } / 4$ \\
$2-1$ & 0.5 & $\left(P_{S}\right)_{\max } / 4$ \\
$2-2$ & 0.5 & $\left(P_{S}\right)_{\max } / 2$ \\
$2-3$ & 0.5 & $3\left(P_{S}\right)_{\max } / 4$ \\
$3-1$ & 0 & $\left(P_{S}\right)_{\max } / 4$ \\
$3-2$ & 0 & $\left(P_{S}\right)_{\max } / 2$ \\
$3-3$ & 0 & $3\left(P_{S}\right)_{\max } / 4$ \\
$4-1$ & $\bar{h}=0 ; \bar{h}=0.5 ; \bar{h}=1.0$ & $\left(P_{S}\right)_{\max } / 4$ \\
$4-2$ & $\bar{h}=0 ; \bar{h}=0.5 ; \bar{h}=1.0$ & $\left(P_{S}\right)_{\max } / 2$ \\
$4-3$ & $\bar{h}=0 ; \bar{h}=0.5 ; \bar{h}=1.0$ & $3\left(P_{S}\right)_{\max } / 4$ \\
\hline
\end{tabular}


profile; $b$ - coefficients depending on the air outlet angle, then the value $\delta_{0}$ and $b$ given accordingly. To find the coefficient $m$ use the regression method. After determining the coefficients of the regression equation, we will get an approximate mathematical model to evaluate the coefficient $m$ in the S-shaped-shaped working blades:

$$
\begin{aligned}
& m=0.043 \beta_{1}+0.0259 \omega^{2} R-0.733\left(P_{S}+\bar{X}_{f}\right) \\
& -\left(0.229 P_{S}-0.046\right)\left(20 \bar{X}_{f}-9\right) \\
& -\left(7.143 P_{S}-1.429\right)\left(0.121 P_{S}-0.024\right) \\
& +\left(0.0345 P_{S}-0.007\right)\left(\frac{\beta_{1}-38}{5}\right) \\
& -\left(2 \omega^{2} R-5.581\right)\left(0.034 \omega^{2} R-0.095\right) \\
& -\left(20 \bar{X}_{f}-9\right)\left(0.82 \bar{X}_{f}-0.037\right) \\
& -\left(0.004 \beta_{1}-0.147\right)\left(\frac{\beta_{1}-38}{5}\right) \\
& -\left(0.005 \beta_{1}-0.186\right)\left(2 \omega^{2} R-5.581\right) \\
& +\left(0.032 P_{S}-0.006\right)\left(2 \omega^{2} R-5.581\right) \\
& +\left(0.208 \bar{X}_{f}-0.094\right)\left(\frac{\beta_{1}-38}{5}\right) \\
& +\left(0.252 \bar{X}_{f}-0.113\right)\left(2 \omega^{2} R-5.581\right)-0.492
\end{aligned}
$$

Quantitative evaluation of the coefficient $m$ in the cascade of the S-shape using expression (7), the result is shown in (Figure 6). When the contour of the camber line is S-shaped, it will reduce the resistance angle at the oulet of the airflow clearances (Figure 7). The larger this change is the larger, the profile of camber line of S-shape is the more, the diffusion coefficient increases (Figure 8).

Calculating the dependence of the loss coefficient on the diffusion coefficient for the average cross section of the study cascade when giving the $\mathrm{P}_{s}$ for speed $m_{1}<0,65$ compared to the original data, shown in Figure 9.

\section{Analyzing the effect of the blade profile to} the characteristics of the airflow clearances in compressor

For each level of the high pressure compressor (Figure 4), the characteristics of each rotating blades and stationary blades were investigated when changing the annular of the blades (angle $\theta_{2 i}$ ) (Figure 3). Observing the performance of each level when the parameters at the inlet are stable, for each mode of operation of that level. In all of the layout patterns surveyed for each cascade (Figure 10), it was observed that there was a change in the parameters in the end zones, especially in the radial clearances. The loss coefficient (8) in these regions increases with increasing parameter $\theta_{2 i}$ (in which case the convex side of the blade profile is wider).
Simultaneously with the increase $\theta_{2 i}$, the level of compression in the middle part of the airflow clearance between the two blades decreases, resulting from the redistribution of parameters according to height. When decreasing $\theta_{2}$, observing the tendency to reduce the loss coefficient in the centrifugal gap area in the middle of the circulation gap found that the reduction in loss coefficient is negligible (Figure 11):

$$
\xi=\frac{\triangle P^{*}}{\left(\rho_{1} W_{1}^{2}\right) / 2}
$$

When studying the effect of the annular of the blade profile (Figure 12) on the changes of parameters along the blade height through which the air flow (stronger intensity, compared to the rotating blade), It can be seen that there is an uneven trend of increasing at the end of the blade profile, ie at the convex area of the back of the profile (the parameter $\theta_{2 i}$ decreases for the blade direction). When decreasing $\theta_{2 i}$, the loss coefficient increases both in the end area (Figure 13) and in the middle of the clearances. In the case of the convex side of the wide-blade profile, the loss coefficient increases (20-40)\%. With the concave surface of the wide blade profile, the value of the average loss coefficient according to the height in the ring is reduced by $8 \div 10 \%$, then in the middle of the profile the blades of the blade direction the loss coefficient decreases by $10 \%$ with the value $\theta_{2 i}=3^{\circ}$. In the distance away from the exit gaps, a decrease in the angle of airflow obstructs the magnetic flow $1 \div 1.5^{\circ}$.

The distribution of the average loss coefficient according to the height of the impeller and the direction of the blades when changing the annular structure of the blades is shown in Figure 14. The distribution of the diffusion in the flaps along the height of the blade is shown in Figure 15.

\section{CONCLUSIONS}

The paper presents a method of formulating the structure of overlap blades in a compressor when applying the S-shaped blades regarding the circular direction. Obtaining a new model for determining the camber angle in the airflow clearances of the rotating blades which camber line is S-shaped, taking into account the thickness, the strugger angle of the cross section and the air inlet angle.

The article shows that the camber line has been the $S$ shaped blade profile, the camber angle of the air outlet cleareances in a compressor decreases. The larger this change is, the larger the S-shaped profile is and the diffusion coefficient increases.

It has been determined about introducing a annular structure of the rotating blades and stationary blades 

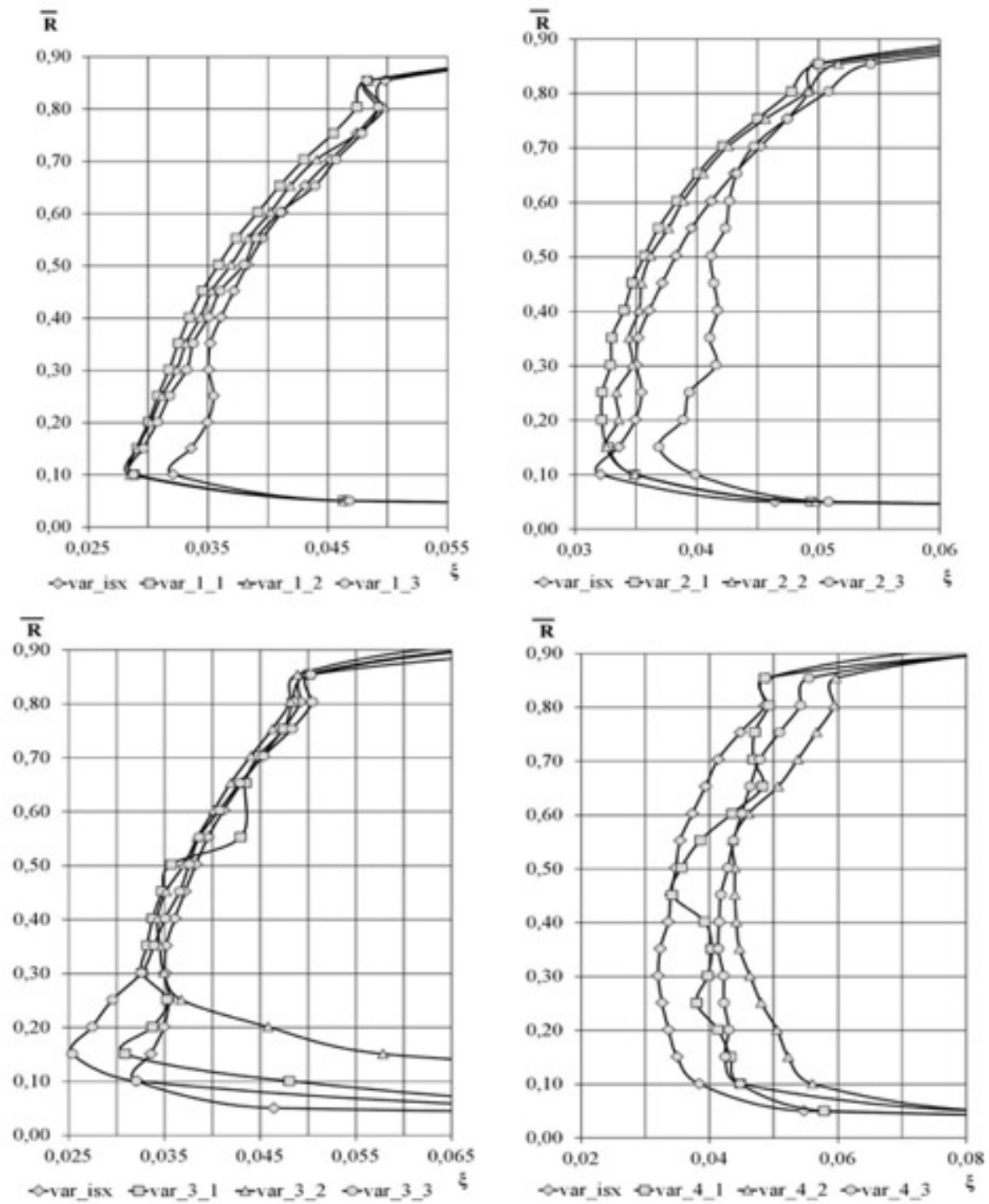

Figure 5: The distribution of the loss coefficients along the profile height of the impeller according to the blade height when choosing different parameters $P_{S}$

in the circular direction, when the concave surface of the blade profile is wide, the loss coefficient within the blade is reduced by $8-10 \%$. In the case of the convex side of the wide blade profile, the loss coefficient increases by $20-40 \%$.

Affirming the good effect of giving the annular structure of the blades, it is achieved mainly by improving the flow structure in the trailing edge of the blades. For the airflow clearance of the stationary blades, the concave surface of the wide blade profile shows a decrease in the strugger angle in the distance from the center $1 \div 1.5^{\circ}$.

\section{CONFLICT OF INTEREST}

We declare that there is no conflict of whatsoever involved in publishing this research.

\section{AUTHOR CONTRIBUTIONS}

All authors contributed equally to this work. All authors have read and agreed to the published version of the manuscript.

\section{REFERENCES}

1. ANSYS CFX [Электронныйресурс]. - Режим доступа. 2012;Available from: http://www.ansys.com/Products/ Simulation+Technology/Fluid+Dynamics/ANSYS+CFX. 


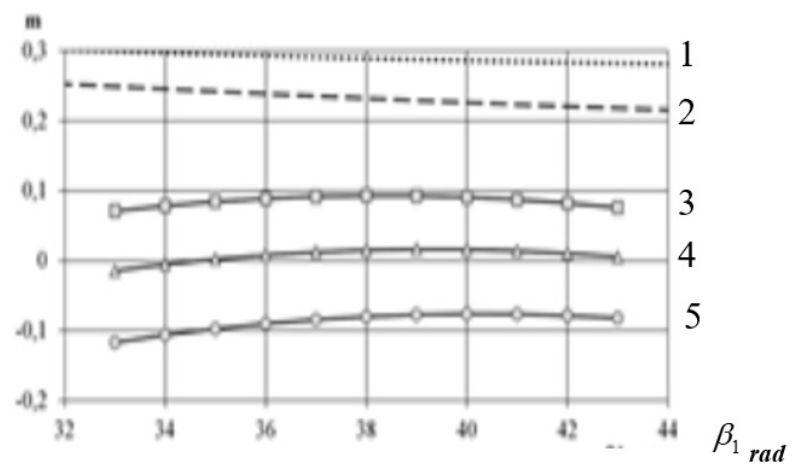

1-Camber line $P_{S}=0.05 \quad$ 2- Camber line $P_{S}=0.15 \quad$ 3- Camber line $P_{S}=0.25$

$$
\text { 4-Camber line } P_{S}=0.15 \quad \text { 5- Camber line } P_{S}=0.25
$$

Figure 6: Dependence of the coefficient $m$ on the air outlet angle of the airflow on the mean cross-section of the rotating blades
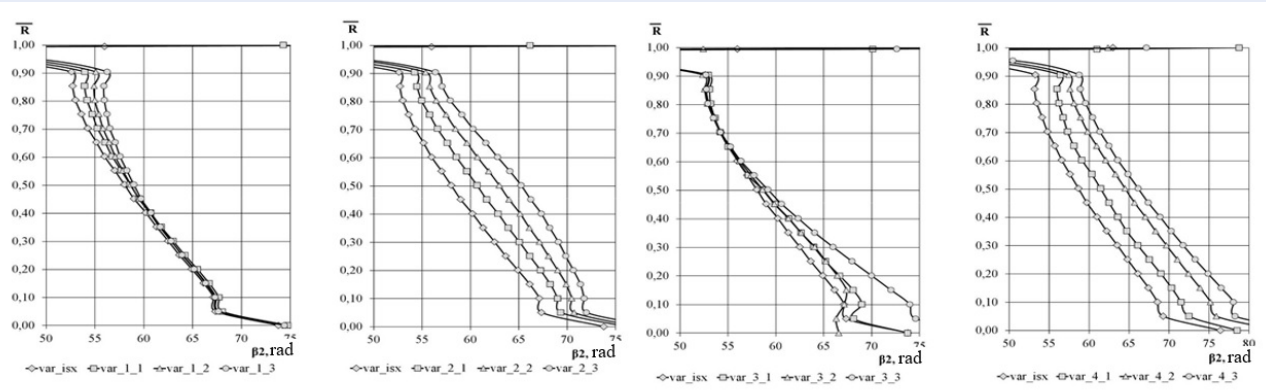

Figure 7: The distribution of the air outlet angle along the blade height of the profile of the rotating blades according to the blade height with various parameter $P_{S}$
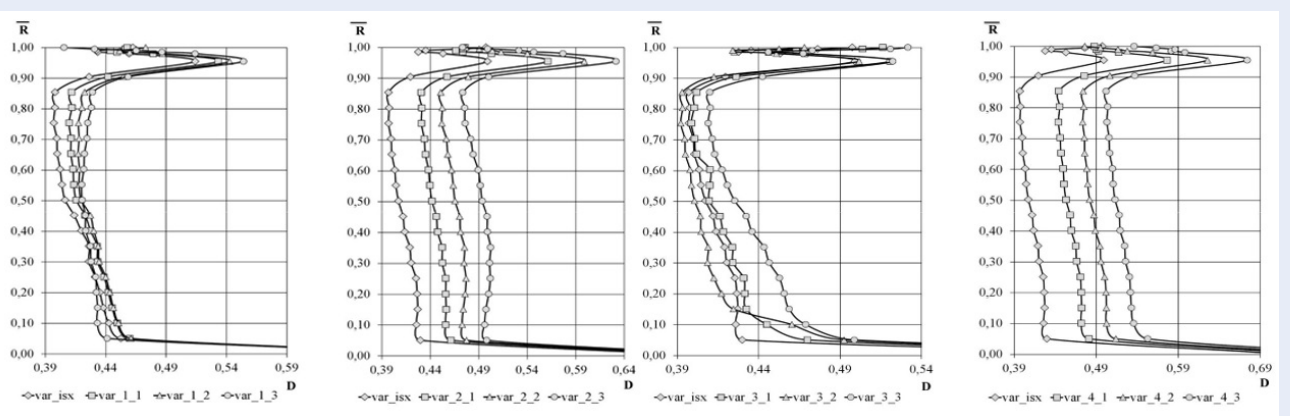

Figure 8: The distribution of coefficient $D$ is along the height of the rotating blades profile with different parameter options $P_{S}$ 


\section{$\xi^{*} \sin (\beta 1) / 2 b / t$}

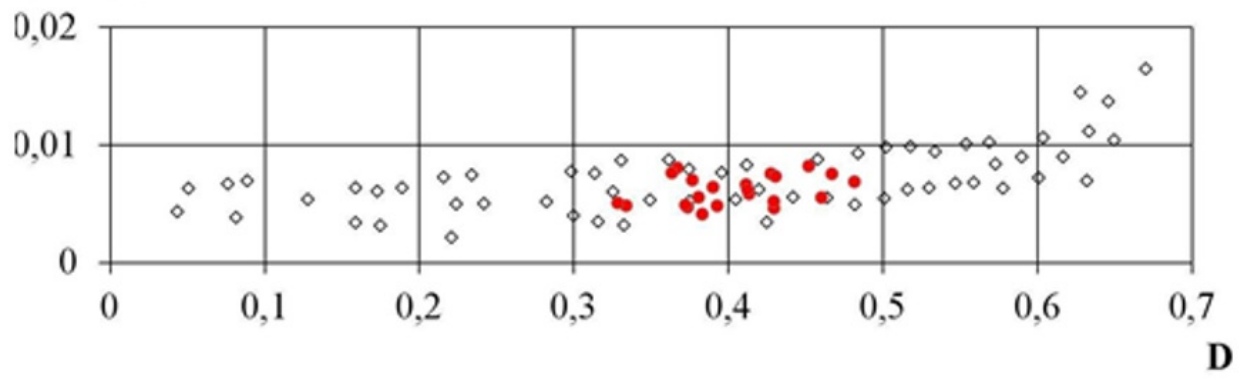

Figure 9: Dependence of $\frac{\xi \cdot \sin \beta_{1}}{2 b t}$ to the diffusion coefficient on the average cross section of the rotating blades (square dots shows the dependence on fine meshing; circle dots show the dependence on meshing in S-shaped profile)
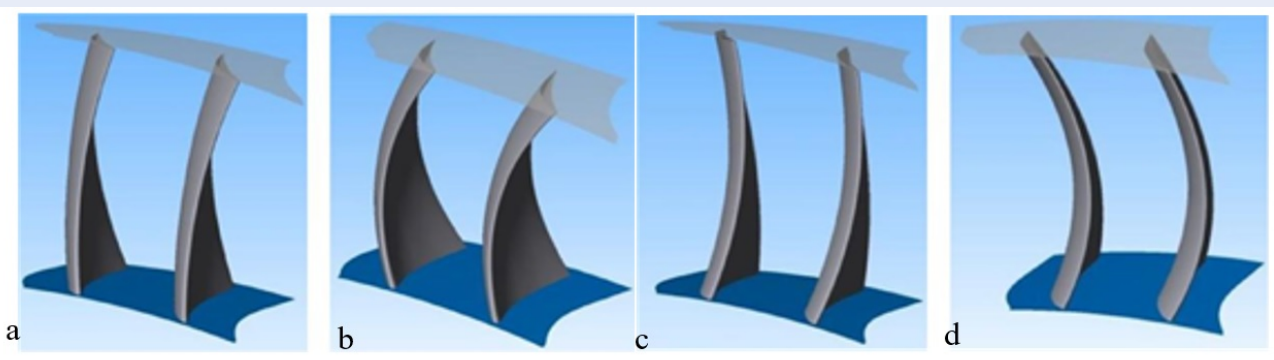

Figure 10: Models of rotating blades $a: \theta=1.5^{\circ} ; b: \theta=3^{\circ} ; c: \theta=-1.5^{\circ} ; d: \theta=-3^{\circ}$

2. Герасименко ВП. Аэродинамическая опти-мизация рабочего колеса компрессора [Текст] / В.П. Герасименко, М.Ю. Шелковский // Авиационно-космическая техника и технология. 2010;10(77):46-48.

3. Комиссаров ГА. Методика газодинамического расчета осевого компрессора. Авиационно космическая техника и технология. 2014;

4. Cục kỹ thuật Hải quân - Thuyết minh kỹ thuật động cơ tuabin khí. 2012;p. 76.

5. The Design, Development and Evaluation of 3D Aerofoils for High Speed Axial Compressors [Text] / D. Lippett, G. Woollatt, P. Ivey, P. Timmis, B. Charnley // ASME paper GT2005-68792.;p. 26.

6. Степанов ЕИ. Расчеты течения в турбомашинах [Текст] / Е.И. Степанов. Авиационно космическая техника и технология . 2014; 


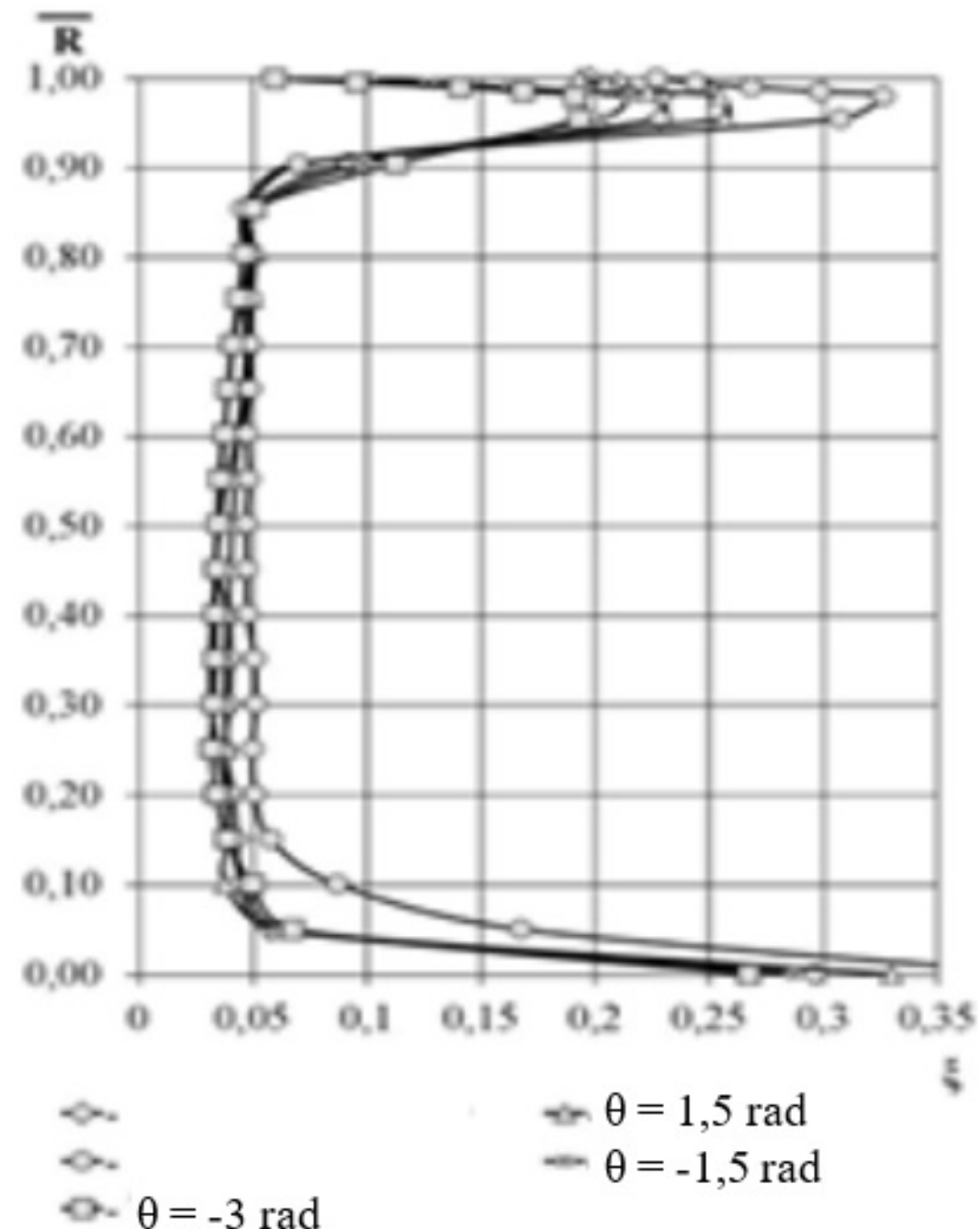

Figure 11: The distribution of the loss coefficient (a) and the air outlet angle (b) in the cascade according to the blade height

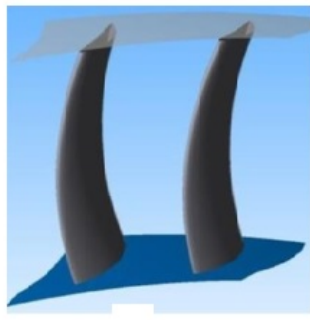

a

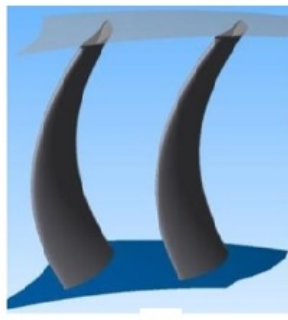

b

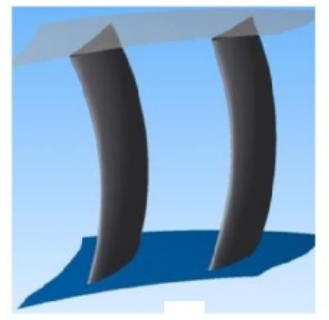

$\mathrm{C}$

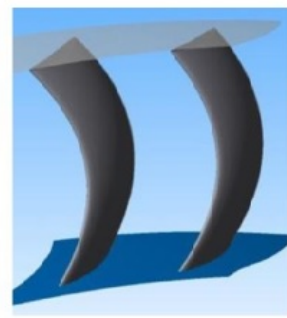

d

Figure 12: Models of blade blades $a: \theta=1.5^{\circ} ; b: \theta=3^{\circ} ; c: \theta=-1.5^{\circ} ; d: \theta=-3^{\circ}$ 

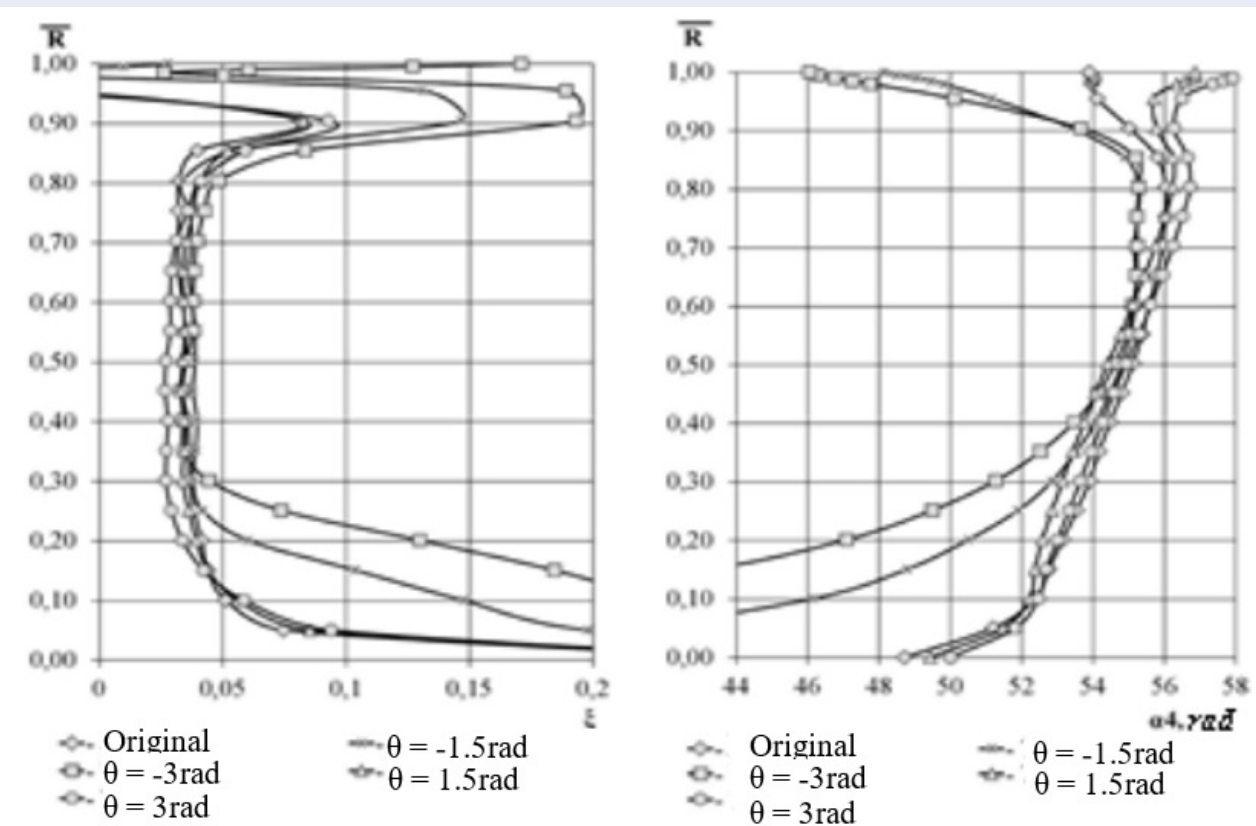

Figure 13: The distribution of the loss coefficient (a) and the angle of exit of the air stream (b) in the ring towards the blade height

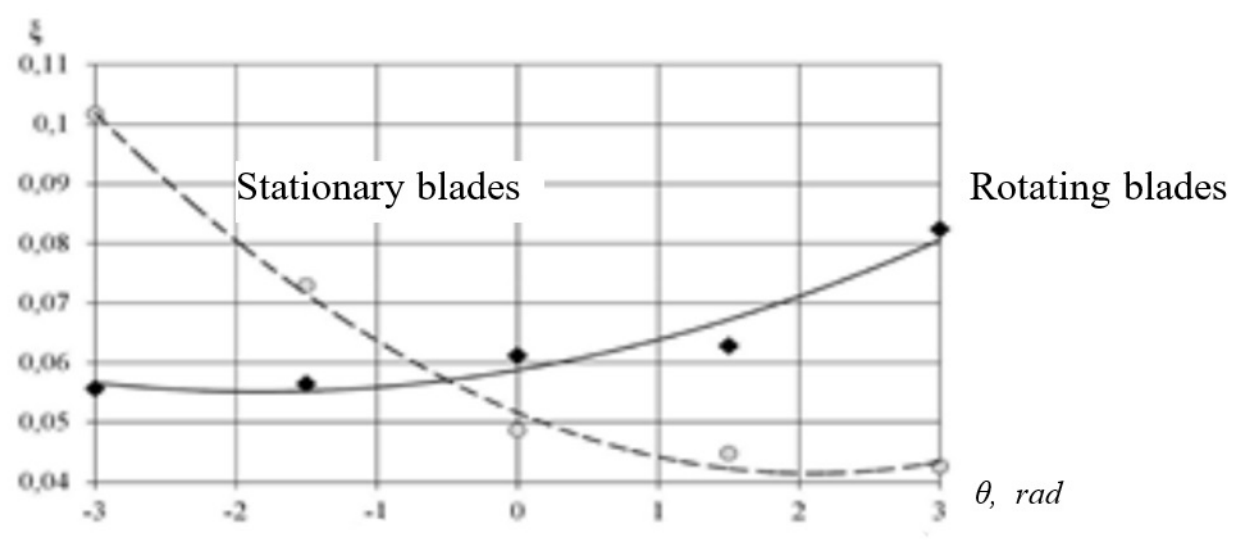

Figure 14: The distribution of the average loss coefficient in the rotating blades and the blade direction when changing the annular form of the blade profile 

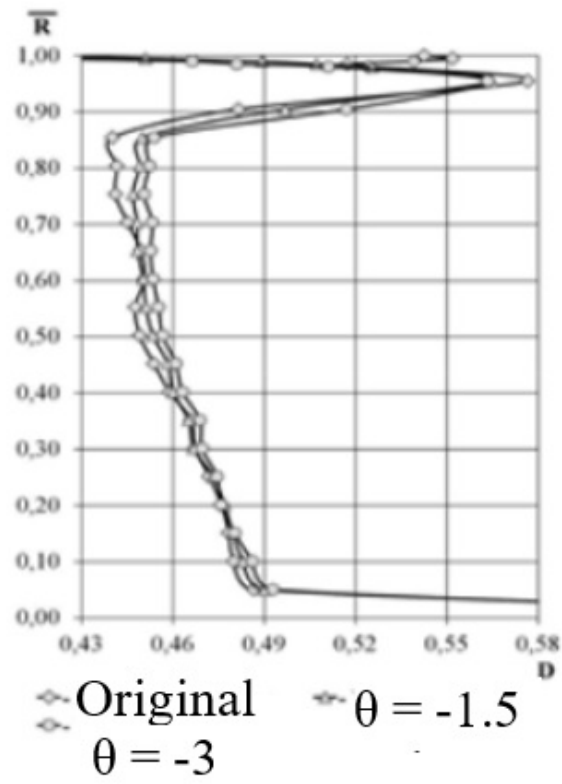

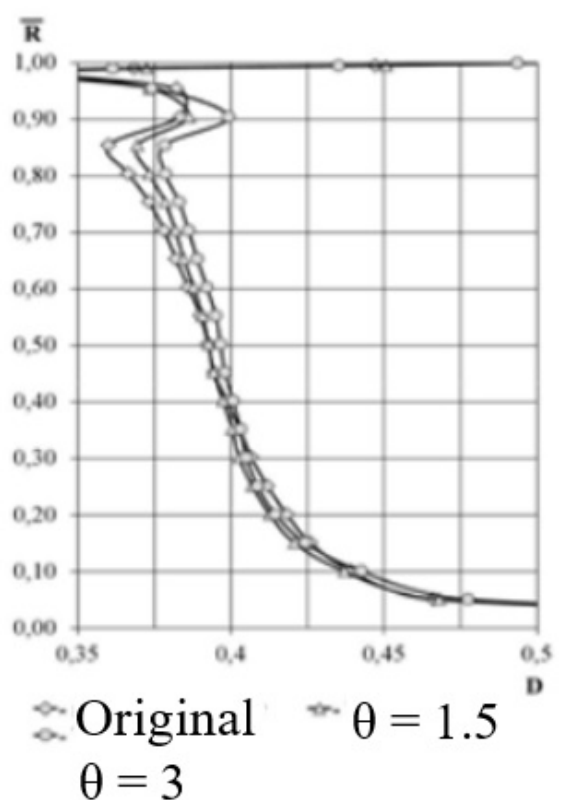

Figure 15: The distribution of the diffusion in the working ring (a) and direction (b) according to blade height 